\title{
Como modificar as regras do jogo a fim de favorecer o setor vitivinícola?
}

\section{Modifying the game rules in order to promote the wine industry?}

\author{
Diego Echevenguá Borges ${ }^{1}$ \\ Adrieli Alves Pereira Radaelli ${ }^{2}$
}

\section{Resumo}

À luz dos conceitos de empreendedorismo institucional e de campos organizacionais, o presente estudo, além de discutir o possível uso do poder de agência inerente ao conceito de empreendedorismo institucional dentro do cenário vitivinícola nacional, busca situar a atual configuração estrutural do setor em alguma das seis perspectivas teóricas referentes ao campo organizacional propostas por Machado da Silva; Guarido Filho e Rossoni (2006). Diante disso, constatou-se que o principal assunto que dinamiza o campo da vitivinicultura brasileira são os impostos que se concentram no contexto do vinho, os quais chegam à taxa de $67 \%$. Tal fato fragiliza a competitividade do setor vitivinícola nacional. Como alternativa de mudança do quadro atual, verificou-se que os representantes dos vitivinicultores brasileiros na Câmara Setorial da Viticultura, Vinhos e Derivados podem fazer uso de mecanismos epistemológicos inerentes ao conceito de empreendedorismo institucional, como persuasão privada e estabelecimento de networkings, com a finalidade de modificar as atuais regras do jogo que regem a vitivinicultura nacional.

Palavras-chave: Indústria vitivinícola brasileira. Impostos sobre o vinho. Empreendedorismo institucional.

\section{Abstract}

Making use of institutional entrepreneurship concepts and organizational fields, this study and to discuss the possible use of agency power inherent in the concept institutional entrepreneurship within the national wine scene and seeks to situate the

1 Doutorando em administração na UFMG. Professor no Centro Universitário UNA - Brasil Email:diego.e.borges@hotmail.com

2 Doutoranda em administração na Universidade de Caxias do Sul - Brasil - Email: adrieli. pereira@hotmail.com 
current structural configuration of the sector in any of the six theoretical perspectives on field organizational proposed by Machado da Silva; Guarido and Rossoni (2006). It was found that the main issue that streamlines the field of Brazilian wine are the taxes on wine, which arrive at the rate of $67 \%$. This fact weakens the competitiveness of the national wine industry. As an alternative to alter the current situation, it was found that representatives of Brazilian winemakers in the sectoral House Viticulture, Wine and Derivatives can make use of epistemological mechanisms inherent in the institutional entrepreneurship concept, such as private persuasion and networkings, to modify the current rules of the game governing the national wine industry.

Keywords: Brazilian Wine Industry. Taxs on wine.Institutionalentrepreunership.

\section{Introdução}

North (1990) sustenta que as instituições são as regras do jogo de uma sociedade. Já as organizações podem ser entendidas como os jogadores. A interação entre instituições e organizações impacta no desempenho econômico. As primeiras procuram diminuir os custos de transação e as incertezas inerentes ao sistema econômico, enquanto as últimas desenvolvem estratégias para responder, de maneira eficaz, às regras do jogo, com o intuito de obter performances positivas em suas atividades.

As regras do jogo incluem instituições formais, tais como as legislações e normatizações oriundas do âmbito governamental, e instituições informais, que podem ser compreendidas como códigos de conduta e de valores incorporados nas crenças sociais. Considerando que comportamento oportunista e contratos incompletos podem estar presentes em diversos tipos de negociações, valores, normas e confiança atuam como mecanismos para aumentar a coordenação e a eficácia das transações econômicas e sociais (AGUILLAR FILHO; FONSECA, 2011).

Sabe-se que os vinhos brasileiros vêm aumentando suas vendas tanto no mercado interno como nas redes internacionais, a partir de incessantes esforços realizados por associações de setor, como o Instituto Brasileiro do Vinho (IBRAVIN), e pelo consórcio Wines of Brasil. Entre as estratégias delineadas, pode-se citar o estabelecimento de um 
escritório no exterior da Wines of Brasil e a realização de parcerias com bares e restaurantes em diversas cidades brasileiras, a fim de difundir o consumo do vinho. No entanto, como apontado pelo IBRAVIN (2013), alcançar um aumento nas vendas tem sido uma tarefa árdua para o setor vitivinícola, tendo em vista que a alta carga tributária sobre os vinhos brasileiros diminui a margem de lucro das vinícolas.

Verifica-se que, apesar dos recorrentes pedidos do setor vitivinícola ao governo nacional para que os impostos sobre os vinhos sejam revistos, não há resposta positiva para que se estabeleça um ambiente regulatório favorável à competitividade da vitivinicultura nacional (NORTH, 1990). Considerando que os impostos sobre os vinhos uruguaios e argentinos giram em torno de $20 \%$ a $30 \%$, os vinhos brasileiros estão em situação desfavorável no mercado vinícola. Entretanto, mesmo sob cenário adverso, o qual resulta em baixas margens de lucros, acredita-se que os conceitos de campo organizacional e empreendedorismo institucional podem oferecer caminhos alternativos às vinícolas brasileiras para sobrepujar os obstáculos elencados.

Oriundos da teoria institucional, os dois conceitos norteadores do texto apresentam-se como mecanismos epistemológicos capazes de substanciar uma análise consistente da problemática vivenciada pelos vitivinicultores brasileiros. De um lado, o conceito de campo organizacional poderá auxiliar na estruturação do ambiente institucional de determinado segmento. De outro, após os resultados obtidos a partir do aparato teórico dos campos organizacionais, insere-se a concepção de empreendedorismo institucional para alinhar ações e estratégias que se encaixem nas demandas dos atores em seus ambientes.

Diante desse contexto, o presente estudo apresenta a seguinte questão de pesquisa: como o setor vitivinícola brasileiro está estruturado e de que forma o conceito de empreendedorismo institucional pode auxiliar no processo de modificação da atual configuração estrutural do setor? Para responder à pergunta, objetiva-se demonstrar como o uso do poder de agência inerente ao conceito de empreendedorismo institucional pode transformar o cenário vitivinícola nacional, assim 
como situar a atual configuração estrutural do setor em alguma das seis perspectivas teóricas relativas ao campo organizacional propostas por Machado da Silva, Guarido Filho e Rossoni (2006).

Ao demonstrar os principais atores e aspectos que estão em discussão no processo de estruturação do campo vitivinícola brasileiro, o presente estudo poderá auxiliar os vitivinicultores brasileiros quanto a diferentes estratégias e ações inerentes ao conceito de empreendedorismo institucional que podem ser engendradas para tornar profícuo o ambiente institucional da vitivinicultura brasileira. Além disso, ainda que diversas pesquisas venham servindo-se de algumas correntes da teoria institucional, como isomorfismo (MAPURUNGA; CORREIALIMA; HOLANDA, 2015; OKADADA, 2014) e respostas estratégicas (CORAIOLA et al., 2015; SOEIRO, 2015), sabe-se que poucos estudos no Brasil (AVRICHIR; CHUEKE, 2011; BARATTER; FERREIRA; COSTA, 2010; GUIMARÃES; CASTRO, 2013; MENDONÇA; ALVES, 2012) têm utilizado a corrente de empreendedorismo institucional como mecanismo epistemológico para analisar diferentes tipos de ações que podem transformar o ambiente institucional. Nesse sentido, ressalta-se que o presente estudo pretende preencher essa lacuna teórica.

\section{Estruturação da vitivinicultura nacional}

De acordo com o mapa da vitivinicultura brasileira elaborado pelo IBRAVIN (2014), a produção de vinhos finos no Brasil concentra-se nos seguintes estados: Rio Grande do Sul, Santa Catarina, Paraná, São Paulo, Minas Gerais, Espírito Santo, Goiás e Bahia.

O Rio Grande do Sul é responsável por cerca de $90 \%$ da produção nacional de vinho, suco de uva e derivados. O estado possuía, em 2012, aproximadamente 50 mil hectares de videiras plantadas e uma produção de uvas que alcançou o total de 840.252 toneladas, enquanto São Paulo, o segundo maior produtor de vinhos, tinha nesse mesmo ano 9.750 hectares plantadas e uma produção de 176.902 mil toneladas de uva. No que se refere à produção de vinhos finos, o Rio Grande do Sul produziu 47.598.471 litros em 2011, enquanto Santa Catarina, o sexto 
maior produtor, chegou a um total de 417.789 litros nesse mesmo ano. Em 2013, a vitivinicultura gaúcha produziu cerca de 48 milhões de litros de vinho fino (DUARTE, 2013; EMPRESA BRASILEIRA DE PESQUISA AGROPECUÁRIA-EMBRAPA, 2013; IBRAVIN, 2014).

Percebe-se que as vinícolas brasileiras têm investido na busca da qualidade do produto, com o intuito de atingir um padrão internacional e competir com os vinhos estrangeiros que chegam ao mercado brasileiro. Nesse contexto, as vinícolas Miolo e Salton são modelos de empresas que se modernizaram e buscaram inserir tecnologias e conhecimento para melhorar a qualidade e, assim, expandir a comercialização de seus vinhos no mercado nacional e internacional (ALIEVI; FENSTERSEIFER, 2007).

Entidades nacionais representativas do setor vitivinícola, como a União Brasileira de Vitivinicultura (UVIBRA), IBRAVIN, Wines of Brasil e diversas associações divididas nos estados produtores, interagem com outras entidades setoriais, como a Associação Brasileira de Enologia, a Associação Brasileira de Bares e Restaurantes (ABRASEL), Secretaria da Agricultura, EMBRAPA Uva e Vinho, Organização Internacional da Vinha e do Vinho (OIV), SEBRAE Nacional, Agência Brasileira de Promoção de Exportações e Investimento (Apex-Brasil), Câmara Setorial da Viticultura, Vinhos e Derivados, Receita Federal, Ministério da Agricultura, Pecuária e Abastecimento (MAPA), Ministério das Relações Exteriores (MRE) e demais órgãos e secretarias que constituem os governos estaduais e o governo federal (IBRAVIN, 2015; MINISTÉRIO DA AGRICULTURA PECUÁRIA e ABASTECIMENTO, 2006).

\section{Método}

Com o intuito de responder aos objetivos de pesquisa, realizou-se uma revisão sistemática, por meio de uma revisão planejada em artigos científicos, dissertações, teses e sites. Nesse processo, apropriou-se de um método sistemático para identificar, selecionar e avaliar criticamente os estudos levantados (ROTHER, 2007; SOUZA; RIBEIRO, 2009). Sabe-se que alguns estudos na área da administração foram realizados 
por meio da referida revisão (BOTELHO; MACEDO; FIALHO, 2010; MEDEIROS et al., 2011; PÓVOA et al., 2012). Para Fink (2008 apud BOTELHO; MACEDO; FIALHO, 2010), a revisão sistemática é um método relevante para ser utilizado nas pesquisas em administração, uma vez que seus preceitos contribuem para o afastamento do viés implícito que o pesquisador pode ter sobre determinado tema.

Primeiramente, estabeleceram-se os objetivos de pesquisa que serviram de guia para realizar os desdobramentos da revisão sistemática. Em um segundo momento, partiu-se para a localização e avaliação crítica dos materiais. Nesse ponto do processo, a análise dos materiais que seriam utilizados como fontes de dados foi baseada em um protocolo de pesquisa desenvolvido com base nas seguintes regras (BOTELHO; MACEDO; FIALHO, 2010): combinação de tudo o que é conhecido sobre um dado tópico e identificação das bases de conhecimento; identificação, avaliação e sintetização de todas as pesquisas disponíveis que são relevantes para responder aos objetivos, escopo de revisão delineado com antecedência; aplicação de padrões para avaliar criticamente a qualidade dos estudos (exemplo: blogs sobre vitivinicultura foram excluídos do escopo da revisão). Com isso, tendo em vista que jornais eletrônicos e sites de associações que representam o setor vitivinícola são um dos principais meios de comunicação dos vitivinicultores com a sociedade, decidiu-se incluí-los no escopo da revisão.

No que se refere às categorias de análise, seguiu-se o procedimento por caixas (BARDIN, 1977), visto que se estabeleceram as categorias a priori, com o objetivo de aplicar os conceitos da teoria institucional ao material coletado. Após a revisão dos materiais coletados, definiram-se as seguintes categorias: campo organizacional e ações e habilidades inerentes ao conceito de empreendedorismo institucional. Por fim, partiu-se para a interpretação dos resultados, momento em que os materiais consultados foram confrontados com as categorias de análise elencadas. 


\section{Contextualização de eventos e análise do campo vitivinícola}

Campo organizacional pode ser caracterizado como unidade fundamental na associação dos níveis organizacional e societário, com a finalidade de analisar o processo de mudança social em determinada comunidade. Tal fato torna o pesquisador mais capacitado para entender a complexa inter-relação entre os ambientes de recursos materiais, competitivo e institucional do que modelos populacionais precedentes (DIMAGGIO; POWELL, 1982, 1986; GUARIDO; FILHO; ROSSONI, 2006; SCOTT, 1991 apud MACHADO-DA-SILVA).

Machado-da-Silva, Guarido Filho e Rossoni (2006) dão margem para a recursividade na construção do ambiente institucional, nos níveis micro (ou seja, no próprio campo) e macro (regras e recursos que inerentes à estrutura). Eles apontam que os agentes não são dopados culturais (BARATTER; FERREIRA; COSTA, 2010), e sim indivíduos que tomam parte na recriação constante das próprias estruturas que os possibilitam expressarem-se como agentes.

As relações entre organizações e outros atores sociais não representam apenas uma estrutura resultante de suas atividades, mas também definem e delimitam suas possibilidades para a ação, numa perspectiva mais interativa e recíproca do processo de institucionalização. Nessa linha de raciocínio, o tratamento do conceito de campo organizacional, com base na noção de estruturação, permite que se incorpore uma lógica de recursividade na análise da relação entre agência e estrutura em um contexto espaço-temporalmente delimitado. (MACHADO-DA-SILVA; GUARIDO FILHO; ROSSONI, 2006, p. 1).

Machado-da-Silva, Guarido Filho e Rossoni (2006) apresentam seis perspectivas teóricas sobre a referida temática: campo como totalidade de atores relevantes; campo como arena funcionalmente específica; campo como centro de diálogo e discussão; campo como arena de poder e conflito; campo como esfera institucional de interesses em disputa; campo como rede estruturada de relacionamentos. No 
Quadro 1, pode-se visualizar as diferentes perspectivas teóricas quanto aos campos organizacionais.

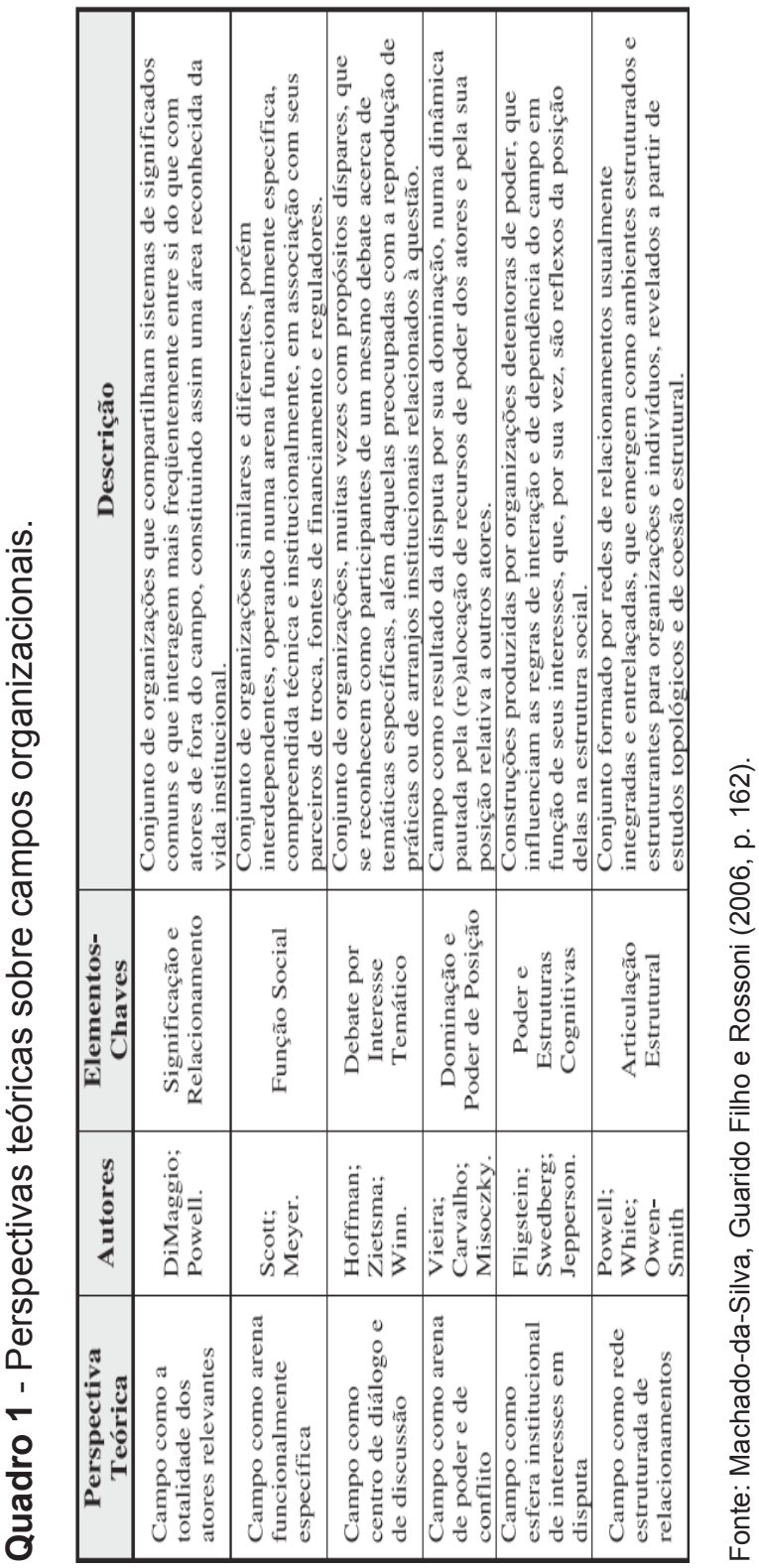


Após a análise dos materiais coletados, decidiu-se enquadrar o campo vitivinícola como um centro de diálogo e discussão. Os trabalhos de Hoffman (1999), Zietma e Winn (2005), Machado-da-Silva, Guarido Filho e Rossoni (2006) expõem que o elemento-chave, nessa perspectiva, é o debate por interesse temático, sendo o campo descrito como:

Conjunto de organizações, muitas vezes com propósitos díspares, que se reconhecem como participantes de um mesmo debate acerca de temáticas específicas, além daquelas preocupadas com a reprodução de práticas ou de arranjos institucionais relacionados à questão. (MACHADO-DA-SILVA; GUARIDO FILHO; ROSSONI, 2006, p. 162).

Com base no pensamento dos antigos neoinstitucionalistas, sabe-se que as organizações tornam-se isomórficas no ambiente institucional em razão do poder das lógicas institucionais de determinar quais ações e comportamentos são legítimos no campo. No entanto, há que se relevar que concepções do velho institucionalismo e dos novos neoinstitucionalistas são passíveis de serem alinhadas na dinâmica transformacional de diversos setores. Isso porque alguns temas, como poder, disputa política, competição mercadológica, crenças sociais, entre outros, possuem a capacidade de tornar o campo organizacional flexível, promovendo, de maneira indireta (ou direta), a reconfiguração do campo a partir da articulação de alguns atores interessados em torno de questões emergentes (HOFFMAN, 1999). Nesse sentido, na visão dos autores, o campo organizacional não se forma em torno de uma tecnologia ou mercado, mas sim por meio de uma questão central que norteará futuros debates entre interesses concorrentes.

Em sua pesquisa sobre o impacto das questões ambientais no campo organizacional da indústria química americana, Hoffman (1999) identificou que, ao longo dos anos, tais questões penetraram no campo sob o aparato de diferentes pilares institucionais. Por exemplo, após a primeira celebração do Dia da Terra, nos Estados Unidos, evento que reuniu mais de 20 milhões de americanos nos campi das faculdades, os políticos perceberam a preocupação da população com as questões 
ambientais. Diante disso, o governo americano criou a Agência Americana de Proteção Ambiental (AAPA). Com a formação da referida agência, o pilar regulador e as instituições que dele emergiam tornaramse o principal meio para coordenar as ações das empresas. Estas, por sua vez, demonstravam oposição às ações governamentais através da mídia impressa.

Por volta de 1983, organizações não governamentais adentraram no campo com maior força, buscando cooperar com a AAPA e com as empresas no combate às atividades industriais danosas ao meio ambiente. Hoffman (1999) argumenta que, naquele momento, o ambientalismo estava passando por uma fase de transição, na qual o pilar regulador estava sendo substituído por instituições normativas, à medida que as empresas incorporavam o discurso da conscientização ambiental.

Transpondo a perspectiva de campo como centro de diálogo e discussão para o momento atual da vitivinicultura nacional, verifica-se que os altos impostos sobre os vinhos finos das vinícolas brasileiras vêm catalisando a dinamicidade no campo. Nesse contexto, as vinícolas e suas associações representativas fazem uso de diversas estratégias para pleitear, junto ao governo federal, a diminuição dos impostos incidentes sobre os vinhos finos, a fim de aumentar a competitividade do setor em nível nacional e internacional.

Em recente matéria publicada no jornal O Tempo (2014), realizada com base no estudo do Instituto Brasileiro de Planejamento Tributário (IBPT), noticiou-se que o vinho brasileiro tem uma carga tributária de quase $60 \%$, dos quais $57,5 \%$ são encargos tributários e $2 \%$ estão divididos entre a contribuição para o Fundo de Erradicação da Miséria (FEM) e os impactos do sistema de substituição tributária. Em outro estudo, encomendado pelo IBRAVIN (2013), verificou-se que os impostos sobre o vinho chegam a 67\%. A título de comparação, no Uruguai, por exemplo, os encargos que acabam sendo pagos pelo consumidor ficam entre $22 \%$ e $23 \%$, segundo o Instituto Nacional de Vitivinicultura do Uruguai (INAVI). Com relação à Argentina, os impostos sobre os vinhos 
giram em torno de $30 \%$ a $35 \%$, de acordo a Corporación Vitivinícola Argentina (COVIAR) (IBRAVIN, 2013).

O imposto sobre o vinho caracteriza-se como uma instituição de ordem regulatória (SCOTT, 2008), pois é uma medida oriunda do poder de legislar atribuído ao governo federal. Como mencionado, nota-se que o campo da vitivinicultura nacional encontra-se estruturado em torno dessa questão. Essa batalha ideológica entre o setor vitivinícola e o governo federal dura mais de uma década. Durante esses anos, a razão defendida pelo governo federal é de que a atual carga de imposto sobre o vinho deve ser mantida pela categoria na qual o setor encaixa-se: o ramo de bebidas alcoólicas.

No entanto, as vinícolas nacionais e suas associações representativas utilizam diversas estratégias, como a mídia impressa e o estabelecimento de networkings com políticos, para tentar modificar a atual carga tributária direcionada ao setor. Revistas e jornais que atentam para assuntos relacionados à economia e aos negócios servem como meio para que o setor vitivinícola possa expor suas carências e requisições. Por exemplo, em matéria intitulada "O paradoxo do vinho brasileiro", a HSM Management digital (2008) apresenta a visão de atores atuantes no setor sobre alguns fatores que deterioram a competitividade do vinho nacional, entre os quais, os altos impostos que incidem sobre o vinho brasileiro. Em uma de suas reportagens, o jornal O Tempo (2014) chama atenção dos seus leitores para a carga tributária direcionada ao setor com o seguinte título: "Imposto pesa sobre vinho nacional e alivia importados”. Nessa matéria, o diretor executivo da Associação Gaúcha de Vinicultores (AGAVI), Darci Dani, salienta que a baixa competitividade do vinho brasileiro perante os importados decorre dos altos impostos sobre os vinhos nacionais.

A articulação política empreendida pelo setor como via para estreitar laços com representantes do governo caracteriza-se como outro tipo de estratégia que visa mobilizar e conscientizar o governo a respeito das necessidades da vitivinicultura nacional. A visita do secretário de Inovação, Nelso Fujimoto, à serra gaúcha, a qual teve como objetivo 
conhecer as diferentes realidades do setor vitivinícola e avaliar de que forma o Ministério do Desenvolvimento, Indústria e Comércio Exterior (MDIC) pode contribuir com a cadeia produtiva, reflete a inclinação do setor em se aproximar de políticos para demandar melhorias estruturais. De acordo com o IBRAVIN (2013), recepcionaram Nelso Fujimoto o diretor Executivo do IBRAVIN, Carlos R. Paviani, o pesquisador da Embrapa e coordenador técnico do Modervitis, José Fernando Protas, e o presidente da Associação dos Vinicultores de Garibaldi (AVIGA), Mario Verzeletti.

Ressalta-se que, durante a visita de Fujimoto, os representantes do setor expuseram as fragilidades da vitivinicultura, reiterando principalmente a necessidade de o governo brasileiro baixar os impostos, a fim de alavancar a força de atuação das vinícolas brasileiras em nível nacional e internacional.

Além do exposto, o estabelecimento da Câmara Setorial do Vinho no Planalto Federal possibilita que as demandas do setor ganhem maior visibilidade, uma vez que os representantes das vinícolas brasileiras estão presentes no cerne da política nacional. Ao atuar diretamente no centro político nacional, acredita-se que se torna maior a probabilidade de tais atores vislumbrarem atalhos para requerer recursos junto aos indivíduos certos. Isto é, buscar auxílio junto a políticos que possuem poder ou capacidade dentro do Congresso Nacional para influenciar outros colegas de trabalho a lutar pelas causas da vitivinicultura nacional. Para Carlos Paviani, diretor do IBRAVIN, a participação da Câmara é importante, porque nela são delineadas propostas concretas que visam consolidar melhorias estruturantes em toda a cadeia vitivinícola. Tais propostas, de acordo com o diretor, são canalizadas diretamente para as instâncias responsáveis pelas políticas nos órgãos de governo (IBRAVIN, 2014).

Quanto ao comportamento das empresas diante desse ambiente institucional desfavorável, Borges (2014) identificou que as vinícolas Dunamis e Miolo resistem e atacam as fontes de pressão institucional (OLIVER, 1991), buscando, junto com suas associações representativas, 
transformar essa situação desfavorável para obter mais vendas e, em consequência disso, aprimorar seus processos e produtos. Segundo as empresas pesquisadas, tal atitude deve-se ao fato de os altos impostos deteriorarem suas economias de escala no próprio mercado nacional. Considera-se significante o comportamento dessas vinícolas no cenário nacional, pois, ao longo dos anos, elas vêm atuando de forma proativa nas mudanças estruturais do setor, por meio do acionamento de diversas estratégias inerentes ao conceito de empreendedorismo institucional.

Percebe-se que ocorreram transformações significativas para setor a partir dos networkings estabelecidos (FLIGSTEIN, 2001) pelas vinícolas nacionais e suas associações representativas com os diversos órgãos governamentais. Por exemplo, vislumbrando conquistar o mercado externo, seis vinícolas nacionais (entre elas, a Miolo e a Dunamis), fazendo uso de propriedades inerentes ao conceito de empreendedorismo institucional, como capacidade de teorização e de estabelecimento de networking setorial para ter maior poder de barganha, pleitearam a criação de um órgão governamental que desse suporte durante seus processos de internacionalização. Como resultado desse esforço, em 2002, criou-se a Wines of Brasil, entidade mantida por uma parceria entre o IBRAVIN e a Agência Brasileira de Promoção de Exportações e Investimentos (APEX-BRASIL), que oferece suporte às vinícolas nacionais que pretendem atingir o mercado externo. Ressaltase que, dos 12,9 milhões de litros de vinhos exportados pelo Brasil nesse período, $61,4 \%$ foram provenientes das vinícolas integrantes do projeto Wines of Brasil (BORGES, 2014; WINES OF BRASIL, 2103).

No final de 2012, após entrarem com pedido de salvaguarda aos vinhos nacionais junto ao MDIC, IBRAVIN, UVIBRA, FECOVINHO e SINDIVINHO, estabeleceram um acordo de cooperação com associações de importadores de vinhos. Em tal acordo, que é entendido, segundo Fligstein (1997), como uma estratégia na qual os empreendedores institucionais requerem cinco recursos para obterem um, decidiu-se que as vinícolas nacionais retirariam o pedido caso o governo e os importadores assumissem os seguintes compromissos: diminuição dos impostos sobre o vinho, suporte aos pedidos de securitização das dívidas 
agrícolas e ampliação para $25 \%$ da presença de vinhos finos brasileiros nas redes de supermercados e $15 \%$ nos demais estabelecimentos varejistas.

Ressalta-se que a categoria analítica que orientou a análise do contexto vitivinícola foi o campo organizacional. Quanto ao resultado obtido, verificou-se que o campo vitivinícola brasileiro é caracterizado como um centro de diálogo e discussão.

Apesar das diversas ações realizadas pelas vinícolas nacionais para tornar o campo vitivinícola nacional estável e profícuo (NORTH, 1990), o governo federal não emite respostas positivas quanto à principal demanda do setor: a diminuição da carga tributária (SINDIVINHOS, 2014). O principal argumento dos governantes para manter o alto imposto sobre os vinhos está relacionado ao fato de tal bebida ser considerada alcoólica (MARKET ANALYSIS, 2008). Isso pode ser considerado crítico, pois os mercados frequentemente exigem mudanças de ordem institucional e tecnológica (VAN BOCKHAVEN; MATTHYSSENS; VANDENBEMPT, 2015).

Nesse sentido, na próxima seção, apontam-se possíveis ações que podem ser utilizadas pelo setor para tornar a vitivinicultura nacional competitiva.

\section{Contextualização de eventos e de empreendedorismo institucional}

A alta carga tributária incidente sobre os produtos e serviços tem elevado a probabilidade de diversas atividades produtivas empreenderem práticas subversivas que obstruem o desenvolvimento do Brasil. Sonegação, contrabando e pirataria difundem-se pela economia nacional, na tentativa de empresários aumentarem suas margens de lucro ao atuarem às margens da lei. O governo, por seu turno, mesmo tendo dificuldade em fiscalizar atividades econômicas localizadas em regiões longínquas, estabelece tributos em demasia sobre algumas atividades produtivas, pois o imposto é considerado a forma mais eficiente e 
direta de manter a máquina estatal financeiramente estável (OLIVEIRA; NASCIMENTO, 2012). Com isso, pode-se constatar os efeitos maléficos da alta tributação no setor vitivinícola ao analisar a recente descoberta feita pela Receita Federal de um esquema de sonegação de impostos que vai de bares a grandes redes de supermercado. Dentre outras constatações, a investigação apontou que os prejuízos aos cofres públicos alcançaram cerca de R \$ 130 milhões (IBRAVIN, 2014). Sabendo que algumas organizações adotam comportamento oportunista em suas transações no mercado (NELSON, 2008), infere-se que a alta carga tributária influencia diretamente na probabilidade de alguns empresários agirem de maneira oportunista e, em consequência disso, empreenderem práticas ilegais com o intuito de sobreviverem no mercado.

Como ressaltado, apesar do cenário adverso, o presente estudo, ao se apoiar na concepção teórica do campo organizacional, em especial no conceito de empreendedorismo institucional, busca elencar possíveis alternativas aos constituintes do setor vitivinícola para que eles delineiem ações consistentes, a fim de tornar as vinícolas nacionais competitivas.

Scott (2008) salienta que somente a partir das duas últimas décadas os institucionalistas começaram a examinar argumentos e situações envolvendo o processo de desinstitucionalização das formas existentes e suas trocas por novos arranjos. Oliver (1992) revela que pressões funcionais, sociais ou políticas podem influir no desaparecimento ou enfraquecimento de leis, normas ou práticas consolidadas em um campo organizacional. Então, verifica-se que pressões funcionais, as quais emergem a partir da percepção de que as atuais instituições impactam negativamente sobre a performance das organizações, vêm sendo canalizadas pelos representantes do setor vitivinícola em direção aos órgãos governamentais, por meio de diversas ações que questionam a tributação incidente sobre os vinhos (SCOTT, 2008).

O ressurgimento do interesse sobre o papel desempenhado pelos atores organizacionais no ambiente possibilitou observar que os sujeitos simplesmente não seguem de maneira passiva os roteiros institucionais. Ao contrário, os indivíduos podem aproveitar certa quantidade de poder 
discricionário para atuar estrategicamente através de agência ativa ou resistência em resposta a tais roteiros.

Os campos organizacionais são espaços frutíferos nos quais as organizações que perseguem resultados distintos unem-se para desenvolver entendimentos coletivos a respeito de questões que são primordiais para manter a estabilidade em determinado campo (WOOTEN; HOFFMAN, 2008). Além disso, no processo de desinstitucionalização de leis e normas prevalecentes no campo, a utilização de propriedades inerentes ao conceito de empreendedorismo institucional pode ser concebida como uma estratégia eficaz (RAO; MONIN; DURANT, 2003 apud SCOTT, 2008). Tendo em vista as assertivas prático-conceituais, assevera-se que, pelo fato de os atores do setor vitivinícola não terem internalizado como legítimos os altos impostos sobre os vinhos, os sujeitos envolvidos poderiam modificar essa regra do jogo (NORTH, 1990) ao se utilizarem de mecanismos epistemológicos oriundos da teoria institucional.

Nesse contexto, o conceito de empreendedorismo institucional, que foi empregado dentro do âmbito do institucionalismo pela primeira vez por DiMaggio (1988), apresenta-se como um mecanismo epistemológico oportuno para entender como a atual configuração institucional da vitivinicultura nacional pode ser modificada a fim de favorecer as atividades vitivinícolas. O autor relaciona o empreendedorismo com a maneira pela qual os agentes empregam recursos com o objetivo de desenvolver e/ou dar poder às instituições. Novas instituições emergem quando empreendedores institucionais, sob o aparato de diversos recursos (financeiros ou estratégicos), organizam-se com o intuito de alcançar objetivos consideravelmente importantes para a execução de suas atividades.

Entretanto, não se pode interpretar o empreendedor institucional como um Deus ex machina. A instituição é o resultado de um processo intersubjetivo (que deve ser reconhecida por outros agentes) e cognitivo (dependentes das habilidades cognitivas de outros agentes), logo, a ação do empreendedor institucional depende de vários fatores, como a 
configuração histórica, política e social de dado ambiente institucional, a necessidade da cooperação de outros agentes e a disponibilidade de recursos para engendrar suas ações (FLIGSTEIN, 2001). Nesse sentido, percebe-se que a estrutura condiciona a ação dos agentes, mas não inibe que os próprios sujeitos possam modificá-la à medida que evoluem, processo marcado por mudanças em formas de comunicação, relações de poder e aumento de questionamento das normas que coordenam a rotina no campo (JACOMETTI; BARATTER; GONÇALVES, 2013).

Empreendedores institucionais podem ser indivíduos, organizações, consultores e grupos profissionais que participam ativamente na criação de novos tipos de instituições, estando presente em tarefas que exigem triar novas tecnologias, designar novas formas de organização e rotinas, criar cadeias de produção e mercados, bem como alavancar o ganho de legitimidade organizacional nas dimensões regulatórias, normativas e cultural-cognitivas. Logo, possuem interesse próprio em ajudar a desenvolver novos padrões dentro de seus setores de atuação, por meio do recrutamento de um conjunto de diversos atores, assim como trabalham para mudar e tentar superar as barreiras de seu ambiente institucional, moldando-o a seu favor por diferentes caminhos (ALDRICH; RUEF, 2006; BECKERT, 1999; SCOTT, 2008).

Estabelecimentos de networkings com stakeholders, persuasão privada, visão de longo prazo, requerimento de recursos junto ao governo nacional e tentativa de sensibilizar os governantes por meio de estudos mostrando que a atual lógica institucional não se mostra eficaz em seus contextos de atuação- estratégia, esta racionalizada por Tolbert e Zucker (1996) como sendo uma capacidade de teorização, fazem parte do rol de estratégias e capacidades utilizadas por empreendedores institucionais para que seus objetivos possam ser atingidos.

Diante do exposto, entende-se que, além dos networkings estabelecidos (FLIGSTEIN, 2001) com políticos que representam diferentes pastas do governo federal, é importante requerer diversos recursos (FLIGSTEIN, 1997) e destacar em relatórios que em países como Uruguai e Argentina os tributos sobre os vinhos são menores, pelo 
fato serem considerados um alimento que faz bem à saúde humana. Ações como essas têm o intuito de sensibilizar o governo, para que ele importe dos países mencionados as lógicas tributárias direcionadas aos vinhos finos (HARDY; MAGUIRE, 2008). Dessa maneira, o setor, aproveitando que atualmente possui um maior poder de barganha devido à criação da Câmara Setorial da Uva e do Vinho, poderia aproximarse do Ministério da Saúde por meio de persuasão privada (LI; FENG; JIANG, 2006), para cooptar membros desse órgão que possuem poder para influenciar outros atores que também atuam no Palácio do Planalto.

Mendonça, Alves e Campos (2010) evidenciaram um processo semelhante ao proposto no parágrafo anterior. Eles constataram que médicos sanitaristas, ao observarem, no início da década de 1980, a manifestação do Vírus da Imunodeficiência Humana (HIVIAIDS) no Brasil, assumiram importantes posições no ambiente institucional, ao fazerem uso de estratégias inerentes ao conceito de empreendedorismo institucional. Os médicos dotados de visão de longo prazo vislumbraram que as enfermidades advindas com a doença alastrar-se-iam pelo o país. Nesse contexto, legitimados junto ao governo federal, munidos de conhecimento científico e de capital político, ocuparam espaços importantes no desenho do próprio modelo do Sistema Único de Saúde, que, anos mais tarde, configurou a política nacional HIVIAIDS.

Em outro estudo, também à luz do conceito de empreendedorismo institucional, Mendonça e Alves (2012) expõem que as associações de classe possibilitam que os agentes tenham força e coordenação na elaboração de novas propostas para seus campos de atuação.

Nesse sentido, o objetivo de estabelecer laços fortes com membros do Ministério da Saúde para, posteriormente, empreender persuasões privadas está diretamente relacionado com a tentativa de tornar as lógicas que circundam o campo vitivinícola conflitantes. Assim, baseados em estudos científicos, atores ligados ao setor poderiam expor em reuniões particulares (LI; FENG; JIANG, 2006), com representantes influentes do referido ministério, os benefícios do vinho à saúde humana. 
A persuasão por meio de conhecimento técnico sobre o assunto e capital político no Congresso Nacional poderia surtir resultados positivos.

Somando-se a isso, entende-se que, ao divulgar na mídia o apoio de membros do Ministério da Saúde quanto à necessidade de diminuir os impostos sobre o vinho, devido às benfeitorias para a saúde humana, diversas associações profissionais, como jornalistas, médicos geriatras, enólogos, pesquisadores, professores, donos de bares e restaurantes, ou até mesmo os consumidores da bebida poderiam impor fortes pressões normativas e/ou culturais cognitivas (caso os consumidores apoiem o setor vitivinícola) contra a posição do governo.

Machado da Silva, Valter e Cruz (2009) apresentam, em seu estudo, que moradores da cidade francesa Aniene articularamse com políticos da região e mobilizaram produtores e moradores da localidade para defender a produção artesanal dos vinhos das pequenas propriedades, a fim de impedir que a multinacional Mondovi instalasse sua produção industrial de vinho na região. Diante disso, acredita-se que o delineamento de concepções inerentes ao conceito de empreendedorismo institucional pode fortalecer o poder de agência dos vitivinicultores brasileiros no processo de modificação das atuais regras do jogo (NORTH, 1990).

\section{Considerações finais}

Este texto foi desenvolvido como ensaio teórico, com o objetivo de discutir o possível uso do poder de agência inerente ao conceito de empreendedorismo institucional dentro do cenário da vitivinícola nacional e situar a atual configuração estrutural do setor em alguma das seis perspectivas teóricas sobre campo organizacional, propostas por Machado-da-Silva, Guarido Filho e Rossoni (2006).

A partir deste estudo, verificou-se que a alta taxa de impostos nacionais sobre o vinho brasileiro torna débil a atividade do setor no mercado nacional. Tal quadro de fragilidade pode ser transposto na análise da atuação do vinho brasileiro no mercado externo, pois se sabe 
que, em diversos países, como Uruguai e Argentina, essa bebida é interpretada como alimento humano. Esse tratamento recebido pelo vinho em países concorrentes faz com que os impostos sobre esse produto sejam consideravelmente menores aos incidentes sobre o vinho nacional.

Acredita-se que o sucesso dos vitivinicultores brasileiros nesse jogo ideológico contra o governo nacional poderia surtir efeito a partir do momento em que os membros do Ministério da Saúde fossem ao encontro da causa. Por meio de persuasão privada, os líderes do setor vitivinícola no Planalto Nacional poderiam apresentar aos membros do referido ministério as causas do setor e os benefícios do vinho ao ser humano. Munidos de capital político e conhecimento científico sobre a saúde, poderiam argumentar que a alta carga tributária agride o setor vitivinícola e as condições financeiras das pessoas que consomem o produto, diminuindo o consumo e, consequentemente, privando estas de tomarem uma bebida benéfica à saúde humana. Como resultado, os impostos poderiam ser repensados a partir do enfraquecimento da lógica de pensamento defendida pelo governo brasileiro.

O pensamento de Thornton (2004) dá margem à reflexão sobre a possibilidade de se conseguir a baixa nos impostos sobre o vinho nacional, pois o autor assevera que empreendedores institucionais possuem a capacidade de perceber diferenças, fragmentações e contradições que abrem espaço para a inserção de novas lógicas institucionais. Como se pode perceber ao longo do texto, de forma natural (ou instintivamente), os vitivinicultores já estão acionando estratégias oriundas do conceito de empreendedorismo institucional nesse duradouro processo de negociação com o governo federal. Diante desses fatos, entende-se que as experiências obtidas pelo setor vitivinícola no cenário político podem facilitar a percepção de fraquezas no discurso a favor dos altos impostos, o que, por sua vez, poderão incitar o delineamento de novas estratégias para melhorar, definitivamente, o corrente quadro da vitivinicultura nacional.

Cabe ressaltar que o ímpeto dos autores da presente pesquisa em delinear as possibilidades de mudança das regras do jogo na vitivinicultura 
nacional, por meio do uso do poder de agência aos vitivinicultores, tem por base a crença de que o sujeito tem voz na construção da estrutura social. Tal fato pode ser verificado, por exemplo, na pesquisa de Mendonça, Alves e Campos (2010), que foi referenciada na seção anterior, assim como em outros diversos estudos não mencionados neste estudo, mas que fazem uso do conceito de empreendedorismo institucional para explicar a mudança e/ou a criação de instituições (DIELEMAN; SACHS, 2008; MAGUIRE; LAWRENCE; HARDY, 2004; MUTCH, 2007).

É válido ressaltar que as ações estratégicas baseadas no conceito de empreendedorismo institucional apresentadas no presente estudo não são racionalizadas como alternativas únicas, mas sim como mecanismos epistemológicos que fazem parte de uma realidade maior. Todavia, ao estarem ao alcance dos vitivinicultores, podem oferecer-lhes perspectivas de ação para modificar as atuais regras do jogo.

\section{Referências}

AGUILLAR FILHO, H. A.; FONSECA, P. C. D.. Instituições e Cooperação Social em Douglas North e nos Intérpretes Weberianos do Atraso Brasileiro. Estudos Econômicos. São Paulo (USP), v. 41, n. 3 p. 551- 571, 2011.

ALDRICH, H. E.; RUEF, M. Organizations Evolving. Second Edition. Thousand Oaks - California: Sage Publications. 2006. 344p

ALIEVI, R. M.; FENSTERSEIFER, J. E. Relações de cooperação e criação de vantagens competitivas: um estudo no arranjo produtivo vinícola da região da serra gaúcha - Brasil. In: DOTTO, DALVA M. E.; MATUELLE, JUVIR, L. Estudos organizacionais: desafios Contemporâneos. Santa Cruz do Sul - RS : Edunisc, 2007. p. 69-92.

AVRICHIR, I.; CHUEKE, G. V. Empreendedorismo institucional: Uma análise de caso no setor de energia elétrica brasileiro. RAM- Rev. Adm. Mackenzie, Edição Especial. São Paulo, v. 12, n. 6, p. 140164., Nov./Dez. 2011. 
BARATTER, M. A. ; FERREIRA, J. M. ; COSTA, M. C..

Empreendedorismo Institucional: características da ação intencional.

Perspectivas Contemporâneas. Campos do Mourão: Edição

Especial, p. 237-266, Out., 2010.

BARDIN, L. Análise de Conteúdo. Lisboa: Edições 70. 187p. 1977.

BECKERT, J. Agency, Entrepreneurs, and Institutional Change.

The Role of Strategic Choice and Institutionalized Practices in

Organizations. Organization Studies, [S.I.], v.20 n.5, p.777-799, Sep., 1999.

BORGES, D. E. Respostas estratégicas ao ambiente institucional e a performance exportadora: o caso dos empreendedores do setor vitivinícola da Campanha Gaúcha. 2014. 157f. Dissertação (Mestrado em Administração). Programa de Pós Graduação em Administração da Universidade Federal de Santa Maria, Santa Maria, 2014.

CORAIOLA, D. M.; JACOMETTI, M.; BARATER, M. A.; GONÇALVES, S. A.. Conciliando Agência e Contexto na Dinâmica da Mudança Institucional. Cadernos EBAPE.BR (FGV), Rio de Janeiro, v.13, n.4, out./dez., 2015.

BOTELHO, L. L. R.; MACEDO, M. ; FIALHO, F. A.. Revisão

Sistemática sobre a Produção Científica em Aprendizagem Gerencial. In: Encontro da ANPAD, XXXIV, 2010, Rio de Janeiro. Anais...Rio de janeiro: ANPAD, 2010, p. 1-14.

DIELEMAN, M.; SACHS, W. M. Coevolution of Institutions and Corporations in Emerging Economies: How the Salim Group Morphedinto an Institution of Suharto's Crony Regime. Journal of Management Studies, [S.I.], v. 45, n.7, pp. 1274-1300. Nov.. 2008.

DIMAGGIO, P. Interest and agency in institutional theory. In: ZUCKER, L. G. Institutional patterns and organizations: culture and environment. Cambridge: Ballinger Publishing Company, 1988. p. 3-21. 
DUARTE, V. N. . Estudo da Cadeia Produtiva do Vinho em Santa Catarina: Características e Estágio Atual. Evidência (Unoesc), Joaçaba, SC, v. 13, n. 1, p. 41- 56, 2013.

EMPRESA BRASILEIRA DE PESQUISA AGROPECUÁRIA. Vitivinicultura Brasileira: Panorama 2012. 2013. Disponível em: <http://www.cnpuv.embrapa.br/publica/comunicado/cot137.pdf.>. Acesso: 02 dez. 2014.

FLIGSTEIN, N. Social Skill and Institutional Theory. American Behavioral Scientist. [S.I.], v. 40 n. 4, p. 397- 405, Feb., 1997.

. Institutional entrepreneurs and cultural frames: The case of the European Union's single market program. European Societies, [S.I.], v.3, n.3, pp. 261-287, 2001.

GUIMARÃES; T. B. C.; CASTRO, L. Estratégia como Prática Organizacional e Empreendedor Institucional: Possibilidades Analíticas a partir do Trabalho Institucional como Prática Social. In: Encontro da ANPAD. Rio de Janeiro, XXXVII, 2013. Anais...Rio de Janeiro: ANPAD, 2013, p. 1-16.

HARDY, C.; MAGUIRE, S.; Institutional Entrepreneurship. In: GREENWOOD, R.; OLIVER, C.; SAHLIN, K.; SUDDABY, R. The Sage Handbook of Organizational institutionalism. London: Sage Publications. 2008. 822 p.

HOFFMAN, A. Institutional evolution and change: Environmentalism and the US. chemical industry. Academy of Management Journal, [S.I.], v. 42, n. 4, pp. 351- 371, Aug, 1999.

HSM MANAGEMENT. O paradoxo do vinho brasileiro. 2012.

Disponível em: <http://www.hsm.com.br/artigos/o-paradoxo-do-vinhobrasileiro.>. Acesso: 06 dez. 2014.

IBRAVIN. Estudo comparativo 2004-2013. 2014. Disponível em: <http://www.ibravin.org.br/public/upload/statistics/1384783926.pdf.>. Acesso: 02 dez. 2014. 


\section{Câmara Setorial da Uva e do Vinho debate temas}

estruturantes. 2014. Disponível em: <http://www.ibravin.org.br/ noticias/172-camara-setorial-da-uva-e-do-vinho-debate-temasestruturantes.>. Acesso: 12 dez.2014.

. Estudo comparativo 2004-2013. 2014. Disponível em: <http://www.ibravin.org.br/public/upload/statistics/1384783926.pdf.>. Acesso: 02 dez. 2014.

. Jornal capixaba noticia esquema de sonegação de impostos no varejo de vinhos. 2014. Disponível em: <http://www. ibravin.org.br/noticias/212-jornal-capixaba-noticia-esquema-desonegacao-de-impostos-no-varejo-de-vinhos.> . Acesso em: $01 \mathrm{dez}$. 2014.

Abrasel e Ibravin alinham projetos para 2014 . 2013.

Disponível em : <http://www.ibravin.org.br/noticias/48-abrasel-e-ibravinalinham-projetos-para-2014.>Acesso: 29 nov. 2014.

- Secretário de Inovação do Mdic visita a Serra Gaúcha para conhecer melhor a realidade do setor vitivinícola. 2013. Disponível em: <http://www.ibravin.org.br/noticias/68-secretario-deinovacao-do-mdic-visita-a-serra-gaucha-para-conhecer-melhor-arealidade-do-setor-vitiv.>. Acesso: 08 dez. 2014.

. Wines of Brasil abre escritório nos Estados Unidos. 2013.

Disponível em: <http://www.ibravin.org.br/noticias/6-wines-of-brasilabre-escritorio-nos-estados-unidos.>. Acesso:29 nov. 2014.

. Mapa brasileiro da vitivinicultura. Disponível em: <http:// www.ibravin.org.br/regioes-produtoras.> Acesso: 01 dez. 2014.

. Tributação do setor vitivinícola brasileiro pode chegar a $67 \%$ do preço final dos produtos. 2013. Disponível em: <http://www. ibravin.org.br/int_noticias.php?id=1028\&tipo=N.> Acesso: 21 jul. 2013.

Sobre o IBRAVIN. 2015. Disponível em: http://ibravin.org.br/ institucional.php. Acesso: 04 jan. 2015. 
JACOMETTI, M.; BARATTER, M. A.; GONÇALVES S. A.. Análise da Estratégia pela Perspectiva das Teorias Institucional e da Estruturação. Revista Eletrônica de Estratégia \& Negócios , Florianópolis, v. 6, n. 3, pp. 125-155, set./dez., 2013.

JORNAL O TEMPO. Imposto pesa sobre vinho nacional e alivia importados. 2014. Disponível em: <http://www.otempo.com. br/capa/economia/imposto-pesa-sobre-vinho-nacional-e-aliviaimportados-1.931344.>. Acesso: 11 dez. 2014.

LI, D. D.; FENG, J.; JIANG, H. Institutional entrepreneurs. American Economic Association, [S.I.], v. 96, v. 2, p. 358- 362, may, 2006. MACHADO-DA-SILVA, C. L. ; GUARIDO FILHO, E. R. ; ROSSONI, L. . Campos Organizacionais: seis diferentes leituras e a perspectiva da estruturação. RAC. Revista de Administração Contemporânea (Impresso), Rio de Janeiro, v. 14, Edição especial, p. 109- 147, 2006.

MAGUIRE, S.; LAWRENCE, T. B; HARDY, C. Institutional entrepreneurship in emerging fields: HIVIAIDS treatment advocacy in Canada. Academy Management Journal, [S.I.], v. 47, n. 5, p. 657679, Oct, 2004.

MARKET ANALYSIS. Estudo do mercado brasileiro de vinhos tranquilos e espumantes Relatório: Qualitativo - Oferta. Disponível em: <http://www.ibravin.org.br/public/upload/downloads/1402930981. pdf.>. Acesso: 12 dez. 2014.

MAPURUNGA, P. V. R.; CORREIA-LIMA, B.C.; HOLANDA, A. P. Disclosure social e isomorfismo nas empresas listadas no índice de sustentabilidade empresarial. Revista de Administração da UFSM. Santa Maria - RS, v. 8, n. 2, p. 267- 281, abr./jun, 2015

MEDEIROS, M. L. ; ALVES, T. ; PASSADOR, J. L. ; PASSADOR, C. S. . Administração e políticas públicas em educação: uma revisão sistemática da produção do EnANPAD e EnAPG de 1997 a 2009. Revista de Ciências da Administração, Florianópolis, v. 13, n. 30, p. 
61-87, maio/ago., 2011.

MENDONÇA, P. ; ALVES, M. A. . Institutional entrepreneurship and professionalization of the rural development of the sisal region in Brazil. RAUSP-e, São Paulo, v. 47, n. 3, p. 489-499, jul./ago./set., 2012.

MENDONÇA, P.; ALVES, M. A.; CAMPOS, L. C.. Empreendedorismo institucional na emergência do campo de políticas públicas em HIV/ AIDS no Brasil. RAE Eletrônica (Online), São Paulo, v. 9, n.1, p. 1-25, jan./jun 2010.

MINISTÉRIO DA AGRICULTURA PECUÁRIA E ABASTECIMENTO. Contribuições das Câmaras Setoriais e Temáticas à Formulação de Políticas Públicas e Privadas para o Agronegócio. 2006. Disponível em: <http://www.agricultura.gov.br/arq_editor/LIVRO_ COMPLETO.pdf>. Acesso: 05 jan. 2015.

MUTCH, A. Reflexivity and the institutional entrepreneur: A historical exploration. Organization Studies, [S.I.], v.28, n. 07, p.1123-1140, july, 2007.

OKADA, S. I. Isomorfismo Institucional, Teoria Crítica e Abordagens Pós-Modernas: Potenciais Emancipatórios ou Uma Nova Jaula de Ferro?. In: Encontro de estudos organizacionais da ANPAD, VIII, 2015, Rio de Janeiro. Anais... Rio de Janeiro: ANPAD, 2014, p. 1-12.

NELSON, R.R.. "What enables rapid economic progress: what are the needed institutions?". Research Policy, [S.I.], v. 37, n. 1, p. 1-11, Feb., 2008.

NORTH, D. Institutions: institutional change, and economic performance. New York: Cambridge University Press.. 1990. 154p

OLIVEIRA, S. B.; NASCIMENTO, F.S. A tributação e a concorrência desleal. 2012. Disponível em: <http://www.egov.ufsc.br/portal/ conteudo/tributa\%C3\%A7\%C3\%A3o-e-concorr\%C3\%AAncia-desleal> . Acesso: 12 dez. 2014. 
OLIVER, C. Strategic responses to institutional process. Academic of management review. [S.I.], v. 16. n. 1, p. 145-179, Jan., 1991

. The antecedents of deinstutionalization. Organization Studies, [S.I.], v.13, n. 4, p. 563- 588. Oct., 1992.

PÓVOA, A. C. S. ; BATAGLIA, W. ; GOUVEA, R. Q. ; TEIXEIRA, M. L. M. . Paradigma Positivista: As diferentes faces de um ilustre desconhecido. In: Encontro de Estudos Organizacionais. VII ENEO, 2012, Curitiba. Anais... Curitiba: ENEO, 2012, p 1-16.

PROTAS, J. F.S.; A produção de vinhos finos: um flash do desafio brasileiro. Agropec. Catarin., Florianópolis, v. 21, n.1, mar. 2008.

ROTHER, E. T. Revisão sistemática X revisão narrativa. Acta paul. enferm. v.. 20, n.2, São Paulo Apr./June, 2007.

SCOTT, R. Institutions and organizations: ideas and interests. Estados Unidos: Sage Publications,, 2008280 p.

SILVA, D. M. Fungos filamentos e micotoxinas em uvas, sucos, mostos e vinhos das regiões sudeste e nordeste do Brasil. 2012. 185f. Tese (Doutorado em Microbiologia Agrícola). Programa de pós Graduação em Microbiologia Agrícola. Universidade federal de Lavras, Lavras. 2013.

SINDIVINHOS-RS. Reivindicação. 2014. Disponível em: <http://www. sindivinhors.com.br/uploads/Informativo\%202014\%20correto.pdf.>. Acesso: 09 dez. 2014.

SOEIRO, T. M.; Pesquisa institucional em contabilidade: uma revisão nos principais periódicos nacionais e internacionais. 2015. 142 f. Dissertação (mestrado em Ciências Contábeis). Programa de Pós Graduação em Ciências Contábeis da Universidade Federal de Pernambuco. Recife, 2015.

SOUZA, M. R.; RIBEIRO, A. L. P.. Revisão Sistemática e Meta-análise de Estudos de Diagnóstico e Prognóstico: um Tutorial. Arq. Bras. 
Cardiol., São Paulo, v. 92, n.3, p. 241-251, mar. 2009.

THORNTON, P. Markets from Culture: Institutional Logics and Organizational Decisions in Higher Education Publishing. Stanford, CA: Stanford University Press. 2004.188p.

TOLBERT, P. ZUCKER, L. The institutionalization of institutional theory. In Stewart CLEGG, S.; HARDY, C.; NORD, W. (Eds). Handbook of Organization Studies, London, ThousandOaks, Sage.. 1996. 895p

UVIBRA. Vinho \& Saúde. As virtudes terapêuticas do vinho. 2009. Disponivel em: <http://www.uvibra.com.br/noticias_virtudes.htm.>. Acesso: 12 dez. 2014.

WOOTEN, M.; HOFFMAN, A. J. Organizational Fields: Past, Present and Future. In: GREENWOOD, R.; OLIVER, C.; SAHLIN, K.; SUDDABY, R. The Sage Handbook of Organizational institutionalism. Thousand Oaks: Sage Publications, CA, 2008.822 p.

VAN BOCKHAVEN, W.; MATTHYSSENS, P.; VANDENBEMPT K. Empowering the underdog: soft power in the development of collective institutional entrepreneurship in business markets. Industrial Marketing Management. [S.I.], v. 48, p.174-186, July, 2015.

Artigo recebido em: 30/04/2015

Aprovado em: 26/01/2016 